In the programme of research which has been under consideration by the Heating and Ventilation Committee of the Department, on which are members of the Institution of Heating and Ventilating

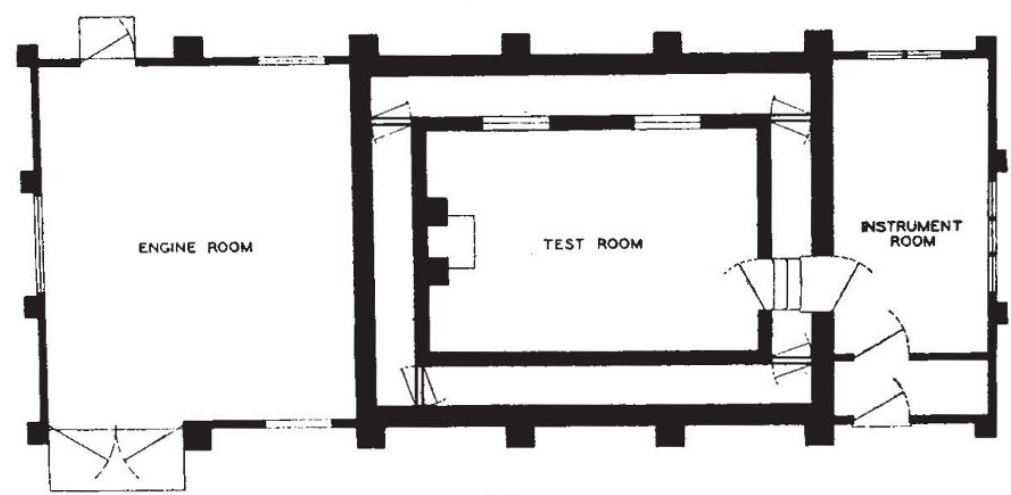

FIG. 2.

Engineers, emphasis has been placed upon the study of the conditions obtaining in a room warmed by extended surface heating and upon the investigation of floor and ceiling heating. It should perhaps be made clear that the new laboratory is specially designed for comparative work, and in the examination of floor heating, for example, it is clearly important to obtain an adequate comparison with other forms of heating. The most common form of central heating in use at the present time is by cast-iron radiators, and it is proposed, therefore, to adopt this as a standard of reference. This will not only provide a very convenient 'yardstick' but will also ensure that a substantial body of data will be obtained relative to this important type of heating.

The new laboratory was open for inspection on the occasion of the annual visit of the Institution of Heating and Ventilating Engineers on July 22, when the members were received by Sir Raymond Unwin, the chairman of the Building Research Board, and the laboratory was formally opened by Sir Frank Smith, secretary of the Department of Scientific and Industrial Research.

\title{
Petroleum Fuels in Canada
}

$\mathrm{D}^{\mathrm{u}}$ URING recent years, importers and consumers of petroleum fuels in Canada have furnished statistics of deliveries and uses of these products to the Department of Mines. Resulting from correlation of data supplied, a report has been prepared entitled "Petroleum Fuels in Canada" (Department of Mines, Bulletin 772; 1936) from which many interesting facts emerge.

Fuels are divided into four classes: fuel oil, kerosene, gasoline and petroleum coke; after summary tables showing quantities of each marketed in Canada during 1933 and 1934, and amounts distributed in each of the Provinces, the classes are studied separately. In 1934 more than 86 per cent of the total fuel oil was processed in Canadian refineries, the rest being imported; of this, 26 per cent was used for domestic heating, 23 per cent for industrial heating and power, more than 5 per cent for tractor fuel and more than 46 per cent for rail and water transportations. In the same year deliveries of kerosene were less than one eleventh of the volume of fuel oil and represented only one twenty-fifth of the total of petroleum fuels; actually only $36 \cdot 2$ million gallons were delivered in Canada, which is substantially less than was delivered in 1933; approximately 66 per cent of this was used for domestic heating, cooking and lighting, 24.5 per cent for tractor fuel and the remainder for other general uses.

Gasoline statistics included in the report are not strictly comparable with those of fuel oil and kerosene as they represent totals recorded by provincial tax departments of the Bureau and are interpreted subject to provisos as to amounts sold, etc., effective each year in each province. The gallonages supplied under each purpose use are therefore treated as estimates; nevertheless tables showing gasoline sales by provinces and quantities sold for motoring and other purposes are of interest as indication of destination of gasoline marketed in Canada.

Petroleum coke is used primarily as a fuel for domestic and industrial heating but is also a useful component of electric batteries, carbon lamps, crucibles and other manufactured articles ; in 1934 approximately 57,000 short tons were sold for fuel, of which about 39,000 tons were destined for domestic heating and 18,000 for industrial heating.

\section{Problems of Translocation in the Plant}

$\mathrm{M}^{\mathrm{s}}$ ESSRS. Mason, Maskell and Phillis continue their analysis of the movement of substances in the cotton plant in two papers published in the Annals of Botany (50, January 1936).

They first give their reasons for rejecting, on present evidence, either the Münch theory of mass flow in the phloem, or the theory of protoplasmic streaming, as providing a satisfactory mechanism for the movements that take place. Any view of mechanism must be influenced by definite information as to whether the phloem can function at the same time to deliver different materials in opposite directions, and these two papers describe the results of experiments designed to elucidate this point. The first paper (by Mason, Maskell and Phillis) shows that whilst very slow import of sugar into darkened 